\title{
HIV-associated Bacterial Pneumonia
}

${ }^{1}$ Charles Feldman MB BCh, DSc, PhD, FRCP, FCP (SA) and ${ }^{2}$ Ronald Anderson PhD

${ }^{1}$ Division of Pulmonology, Department of Internal Medicine, Charlotte Maxeke Johannesburg Academic Hospital and Faculty of Health Sciences, University of the Witwatersrand, Johannesburg, South Africa and ${ }^{2}$ Medical Research Council Unit for Inflammation and Immunity, Department of Immunology, Faculty of Health Sciences, University of Pretoria and Tshwane Academic Division of the National Health Laboratory Service, South Africa.

Acknowledgement: Charles Feldman is supported by the National Research Foundation (NRF), South Africa.

\author{
ADDRESS AND CORRESPONDENCE \\ Professor Charles Feldman \\ Professor of Pulmonology \\ Division of Pulmonology \\ Department of Internal Medicine \\ University of the Witwatersrand \\ Medical School \\ 7 York Road \\ Parktown, 2193 \\ Johannesburg \\ South Africa \\ TEL + $2711488-3840$ \\ FAX + $2711488-4675$ \\ e-mail charles.feldman@wits.ac.za
}

\section{SYNOPSIS}

Community-acquired bacterial pneumonia (CAP) remains one of the most common opportunistic in patients who are HIV-infected, this despite the use of co-trimoxazole prophylaxis and even the introduction of HAART. HIV itself is a risk factor for CAP, but additional risk factors exist and include increased age, previous pneumonia, other co-morbid conditions and also cigarette smoking. The risk of CAP increases as the CD4 cell count decreases. The pathological changes that occur in the immune system as a consequence of 
HIV infection explain the mechanisms associated with the increased risk of CAP. The common bacterial pathogens that cause CAP in HIV-infected persons are similar to those in HIV-non-infected individuals, with the pneumococcus being the most common pathogen. The clinical features of CAP in HIV-infected persons are similar to those in HIV-noninfected persons. However, contrary to the findings of early investigations, many recent studies indicate that the mortality of pneumococcal CAP is higher in HIV-infected patients and the mortality tends to stratify according to the CD4 cell count, being greater at lower CD4 cell counts. While the diagnostic workup of HIV-infected patients with CAP is similar to those cases that are HIV-uninfected, use of the newer rapid laboratory techniques has expidited the diagnosis of these infections. Not only does the mortality remain high in HIVinfected persons with CAP, but the occurrence of CAP is associated with a permanent decline in lung function in these patients. Prevention of CAP remains critical and necessitates a comprehensive approach addressing, among many other factors, cigarette smoking cessation strategies, HAART adherence and immunization against those infections for which effective vaccinations are available.

Keywords: CD4 cell count, community-acquired bacterial pneumonia, HAART, HIV infection, mortality, smoking, treatment, vaccination

\section{INTRODUCTION}

The respiratory tract is recognized to be the site most critically affected as a consequence of human deficiency virus (HIV) infection/acquired immune deficiency syndrome (AIDS) [1]. While in the initial phase of the epidemic the lung was involved in almost $100 \%$ of the cases, currently, in the era of highly active retroviral therapy (HAART), it is involved in some $70 \%$ of the patients [1]. Pulmonary infections are the major component 
of these complications, with lower respiratory tract infections being 25 -fold more common than in the general population. Respiratory infections in general, rather than only AIDSrelated opportunistic infections, remain a major cause of morbidity and mortality and reason for hospital admission [1]. The spectrum of pathogens causing pulmonary infections in HIV infected persons is vast, differs in the various geographical areas, and has changed over the evolution of the epidemic due to the introduction of co-trimoxazole prophylaxis and HAART [1]. Most importantly, the three most common infections, namely tuberculosis (TB), bacterial pneumonia and Pneumocystis pneumonia (PCP), have been documented to result in a worse course of HIV disease, as well as permanent impairment in lung function in most studies [1].

\section{EPIDEMIOLOGY, PATHOGENESIS AND RISK FACTORS FOR BACTERIAL PNEUMONIA}

\section{Epidemiology}

While community-acquired pneumonia (CAP) is usually described as the most frequent pulmonary infection in HIV infected individuals followed by PCP and TB, the relative prevalences of these three infections does vary in the different geographical regions [1]. In the early phases of the epidemic, PCP was the most common infection overall, but this has decreased considerably in prevalence as a consequence of the use of co-trimoxazole prophylaxis initially, and subsequently to the introduction of HAART [1]. Presently in Africa, for example, TB is the most common pulmonary infection, whereas in the US and Western Europe, CAP is the most common [1]. Bacterial pneumonia is also the most common admission diagnosis in patients with HIV infection and occurs with a more than 10fold increased risk of frequency [1]. Undoubtedly, the risk for the development of each of these infections is also influenced by degree of immunosuppresion of the patients, their 
demographic characteristics, their place(s) of residence, their use of prophylaxis and possibly genetic influences [1].

\section{Pathogenesis}

The human lung, with its highly organized network of mediastinal lymph nodes, is a major target of HIV infection [2,3]. Relative to the gastrointestinal tract, however, the rate of immune attrition in the lungs is considerably slower [4-6]. There are several reasons for this, including: i) the mediastinal lymph nodes are the primary sites of $\mathrm{T}$ cell antigen priming in the lung, with secondary bronchus-associated lymphoid tissue being much less prominent than that of the gut-associated secondary lymphoid tissue $[4,7,8]$; ii)) the diversity and efficacy of the innate immune mechanisms of the airways [9]; iii) the relative resistance of lung $\mathrm{CD}^{+} \mathrm{T}$ cells of the Th1 [5] and Th17 [6] subtypes, as well as alveolar macrophages [10], to productive infection with, and depletion by HIV; and iv) initiation of a vigorous antiHIV response mediated by antigen-specific $\mathrm{CD} 8^{+}$cytotoxic $\mathrm{T}$ cells, as well as natural killer (NK) cells and NKT cells [3].

Spread of HIV to the lungs is achieved by several mechanisms including: i) infection of hematopoietic progenitor cells, especially those which differentiate into monocytes; these, in turn, mature into alveolar macrophages and myeloid dendritic cells following trafficking to the lungs [11]; ii) capture of HIV by DC-specific intercellular adhesion molecule grabbing integrin (DC-SIGN) by monocytes and immature DCs, predominantly myeloid DCs, in blood $[12,13]$; iii) infection of these cells, as well as plasmacytoid DCs, with HIV via CD4/CCR5 interactions, albeit at low level [14,15]; and iv) acquisition of the integrins LFA-1 and VLA-4 by HIV during budding from infected cells, promoting attachment to, and productive infection of vascular endothelial cells [16,17].

In spite of the relative resistance of the lungs to HIV-mediated immune attrition, progressive infection inevitably impacts negatively on the numbers and functions of 
pulmonary $\mathrm{CD}^{+} \mathrm{T}$ cells and it is noteworthy, as mentioned earlier, that respiratory infections are the leading cause of mortality in HIV/AIDS. As is the case in other tissues, it is the CD4/CXCR6 co-expressing T cells of the effector/memory phenotype which are most vulnerable $[2,3]$. HIV-mediated depletion of $\mathrm{CD}^{+} \mathrm{T}$ cells is a direct consequence of both productive virus infection [18] and induction of Fas-mediated apoptosis in both HIV-infected and - uninfected cells [19]. In addition to these direct mechanisms of HIV-induced T cell depletion, increasing evidence has implicated chronic activation of plasmacytoid DCs as being an indirect mechanism of T cell dysfunction and cytotoxicity [20,21]. In this setting, pulmonary plasmacytoid DCs interact with HIV via CD4,resulting in internalization of the virus. In the cell cytoplasm, viral RNA is recognized by intracellular pathogen recognition receptors known as Toll-like receptors (TLRs)-7 and -9 [20-23], and possibly by the more recently described cytoplasmic pathogen nucleic acid sensors [24]. This leads, in turn, to excessive and sustained production of: i) type I interferon (IFN); ii) the tryptophan catabolizing enzyme, indoleamine 2,3-dioxygenase; and iii) the cytokine, transforming growth factor $\beta$ (TGF- $\beta$ ), all of which contribute to immune dysfunction [20,25-33]. These immunosuppressive mechanisms are summarized in Table 1 . With respect to TGF- $\beta$ mediated pro-fibrotic activity, it is noteworthy, that extensive fibrosis of the T cell zone of lymphoid tissue has been proposed to be a significant factor in the failure of $\mathrm{T}$ cell reconstitution following initiation of antiretroviral therapy (ART), despite viral suppression [33].

\section{Pneumococcal pneumonia}

The striking association of HIV infection with increased susceptibility for development of bacterial CAP, due in particular to Streptococcus pneumoniae (the pneumococcus), is well recognized and has been the subject of several recent reviews [3,3436]. The risk index increases significantly with advanced disease and associated 
immunosuppression, and is further increased when HIV infection is associated with other risk factors.

Clearly, the adaptive immune responses operative against the pneumococcus are extremely vulnerable to HIV-mediated suppression. Foremost among these are: i) the production of $\operatorname{IgG}$ and secretory $\operatorname{IgA}$ antibodies with opsonophagocytic and adherenceneutralizing properties respectively, directed against capsular polysaccharides; and ii)the generation of $\mathrm{CD}^{+} \mathrm{T}$ cells of the Th1 and Th17 subtypes which target various protein antigens, resulting in production of the cytokines IFN- $\gamma$ and IL-17A respectively. IFN- $\gamma$ promotes activation of alveolar macrophages and neutrophil influx, while IL-17A promotes recruitment and activation of monocytes and neutrophils [reviewed in 37,38]. In the case of the former, the production and reactivity of capsular antibodies are compromised as a consequence of: i)depletion of CD154-expressing memory helper T cells of the Th1 and Th2 subtypes, which provide help to antibody producing B cells [39]; and ii) loss of antigenspecific memory B cells with advancing disease [3]. Progressive loss of Th1 and Th17 cells results from the mechanisms described in the preceding section.

In addition, HIV-associated neutropenia and monocytopenia, as well as dysfunction of several of the protective activities of these cells, including chemotaxis to bacterial proteins, as well as antimicrobial activity, are potential contributors to predisposition to pneumococcal disease $[40,41]$.

Cigarette smoking may cause further impairment of innate and adaptive immune host defences by compromising the protective activities of the mucociliary escalator, as well as those of alveolar macrophages and pulmonary T cells, underscoring the interactions between HIV infection and smoking in promoting colonization of the airways by the pneumococcus, a prerequisite for future development of invasive pneumococcal disease [reviewed in 42]. 
These various mechanisms which predispose the HIV-infected to severe pneumococcal disease are shown in Table 2.

\section{Haemophilus influenzae}

Although less common than the pneumococcus, H.influenzae, usually non-typeable, is a major etiologic agent of pneumonia in the HIV-infected, being most evident in very advanced disease when the total circulating $\mathrm{CD}^{+} \mathrm{T}$ cell count declines to $<100 \mu 1 /$ blood [43]. The risk for development of invasive disease is around 100 times higher than that of HIVuninfected subjects of comparable age [44].

\section{Risk factors}

HIV infection is, itself, a risk factor for pneumonia, and the incidence in infected persons is greater than that in non-infected individuals, although the exact mechanism(s) are uncertain $[35,45]$. While bacterial pneumonia can occur throughout the course of HIV infection the stage of the HIV infection is most consistent [46]. The frequency of CAP has an inverse relationship with the CD4 cell count, occuring most commonly occurs when the CD4 cell count decreases and the median CD4 cell count when pneumonia occurs is said to be 200 cells $/ \mathrm{mm}^{3}$ [1]. It becomes particularly more common in cases with a CD4 cell count below 200 cells $/ \mathrm{mm}^{3}[47]$

Among the specific risk factors for CAP in HIV infected individuals are cigarette and illicit drug smoking and IVI drug use, cigarette smoking being associated with an increased risk of up to 5-fold [1, 46-48]. Studies have suggested that cigarette smoking is associated with poorer virological and immunological responses to HAART and this may explain, at least partly, why patients on HAART have an ongoing increased risk of pneumonia $[34,49,50]$. Furthermore, smoking may also accelerate the progression to AIDS [49,51]. Numerous studies attest to the negative impact of cigarette smoking and the positive benefit of smoking cessation $[34,35,47,52,53]$. 
Additional risk factors include increased age, increased viral load and previous pneumonia, underlying co-morbid conditions, including alcoholism, cirrhosis, asthma, cardiovascular disease, renal conditions and sickle cell disease, malnutrition and lower socioeconomic circumstances (BOX 1) [46].

Effective control of the viral load has a significant positive impact on the risk of the development of pneumonia [1]. Relatively few reports have documented the impact of HAART on the occurrence of pneumonia [1]. There have been some reports suggesting that HAART does decrease the prevalence, being particularly beneficial in patients with a CD4 cell count below 200 cells $/ \mathrm{mm}^{3}$, and more effective with continuous rather than intermittent therapy [1,52], but rates of pneumonia in patients on HAART may still be higher than in the general population $[35,54,55]$. One study documented a persistent high burden of invasive pneumococcal disease in HIV-infected adults, despite a stable prevalence of HIV and an increased roll-out of antiretroviral therapy [56].

\section{ETIOLOGY OF COMMUNITY-ACQUIRED BACTERIAL PNEUMONIA}

An etiological diagnosis is obtained in some $35-75 \%$ of $\mathrm{HIV}$-infected patients with bacterial CAP $[35,46]$. In general, the bacterial etiology of CAP is very similar in HIVinfected and HIV-non-infected individuals (BOX 2). Polymicrobial infections do occur and co-infections with the common bacterial pathogens with any of the other opportunistic pathogens, such as Pneumocystis jirovecii and even Mycobacterium tuberculosis, have been described [57]. Bacteremia is more commonly noted with the bacterial pneumonias and relapses or recurrent infections have also been documented in HIV infected patients [1]. Streptococcus pneumoniae.

As is commonly noted, Streptococcus pneumoniae is by far the commonest cause of bacterial pneumonia, being implicated in some $20 \%$ of cases overall, $40 \%$ of cases in which a 
microbiological diagnosis is made, and $70 \%$ of bacteremic pneumonias $[1,46,48]$. In several studies, such infections have been associated with an increased risk of bacteremia, and rates of invasive pneumococcal disease have been reported to be up to 100-fold higher than that of non-HIV-infected subjects [3,34-36, 46,48].

While recurrent infections are also commonly noted, there has been some data, although conflicting, suggesting that HAART has not had a major impact on the incidence of CAP, and particularly invasive pneumococcal infections, as indicated elsewhere $[1,34]$. Thus even in the post-ART era, the risk for development of invasive disease remains extremely high, being about 35-fold higher than that of the HIV-uninfected [3]. There have also been conflicting data on the impact of prior pneumococcal vaccination on subsequent risk for pneumococcal infections [1].

\section{Haemophilus influenzae}

This pathogen is said to account for approximately $10-15 \%$ of cases of bacterial pneumonia of known microbiological etiology [1,46]. It is more common among patients with advanced HIV disease and usually presents as a subacute infection [1,58]. Quite commonly, both clinically and on chest radiograph, it presents as a diffuse pulmonary infiltrate $[1,58]$. The mortality rate is not higher with this form of pneumonia than that occurring in the general population [58].

\section{Staphylococcus aureus}

This pathogen is said to be the third most common cause of bacterial CAP [1], accounting for some $5 \%$ of cases [54]. For reasons that are quite obvious, this infection is most common among IVI drug abusers and such infections can be associated with endocarditis, with or without septic pulmonary emboli, even in patients without prior evidence of cardiac valvular disease [1]. Recent viral or influenza infection is also a risk factor for this infection [45]. HIV-infected persons are also at increased risk for community- 
acquired methicillin resistant Staphylococcus aureus [59]. When infections with S. aureus are suspected or proven, specific therapy needs to be initiated, but despite appropriate treatment this infection is associated with a high mortality rate [60].

\section{Gram-negative pathogens}

Gram-negative organisms currently account for approximately $5 \%$ of pneumonias in HIV infected persons, and in particular this is due to Pseudomonas aeruginosa [46,61]. Both community-acquired and nosocomial pneumonia infections occur in HIV-infected patients, although infections other than pneumonia are also found [61]. In the pre-HAART era, Pseudomonas aeruginosa was a not unusual cause of community-acquired bacterial pneumonia, while currently, some studies have suggested that much fewer infections are caused by this microorganism $[1,61]$. Since pseudomonal infections occur especially among patients with advanced immunosuppression (CD4 cell counts $<50$ cells $/ \mathrm{mm}^{3}$ ), it follows that after the introduction of HAART, these infections have become much less common $[1,51]$. The mortality rate for pneumonia caused by this microorganism is higher than that for the other, more common, bacterial pathogens [61,62].

\section{Atypical pathogens}

While Legionella infections are said to be relatively uncommon, they appear to occur much more frequently in patients with AIDS, compared to the general population, and may possibly be associated with a more severe clinical course and a worse prognosis $[1,63,64]$. Infections with Mycoplasma pneumonia and Chlamydophila pneumoniae appear to be relatively uncommon causes of pneumonia in HIV-infected individuals, but there are no studies systematically evaluating their exact role $[1,45,51]$.

Other infections

A number of other, less common, bacterial infections also occur. For example, Rhodococcus equi can cause pneumonia in HIV-infected persons, especially in cases with 
advanced immunosuppression, and this pathogen typically causes an infection with an indolent course, with clinical and even radiological features (e.g. cavitation) mimicking those of pulmonary (TB) $[1,51,65]$. For the treatment of both these infections, early initiation of antiretroviral therapy and the use of combination antimicrobial agents is recommended, which needs tapering according to the antimicrobial sensitivity patterns of the cultured isolates $[1,65]$.

Moraxella catarrhalis may also cause pneumonia in HIV-infected patients, especially in those cases with a low CD4 cell count and/or coexisting respiratory diseases, and may be associated with considerable morbidity [66]. Nocardia is an aerobic actinomycete that can cause infections, including pneumonia, usually in association with immunosuppression, including HIV infection $[67,68]$. The clinical course is often chronic, although dissemination can occur and be associated with a high mortality [68]. The diagnosis is frequently delayed and a high index of suspicion is required [68]. Treatment with antimicrobial agents with proven synergy is recommended for initial therapy [68].

\section{CLINICAL PRESENTATION}

In general, it is said that the clinical presentation of bacterial CAP in HIV-infected patients is similar to that occurring in cases that are not HIV-infected [1,35,45]. Patients usually present with the typical features of a cough productive of sputum, fever, rigors, and chest pain together with focal consolidation(s) in the lung [45]. Clinical differences noted include the fact that more of the cases are female, that the patients are younger, more likely to be drug users, and that they have a higher frequency of respiratory symptoms [69]. Presentation with pneumonia may be the first manifestation of underlying HIV infection occurring particularly in younger patients with pneumonia and no apparent risk factors, HIV infection should be considered [45]. There is a spectrum of disease severities, as in HIV- 
uninfected patients, and the commonly used severity of illness scoring indices, such as the PSI and the CURB-65 score, are of equivalent value in predicting severity and/or outcome [48]. The pneumonia most commonly presents as a lobar or segmental consolidation, although patchy consolidation may sometimes occur and occasionally the presentation is as a diffuse reticulonodular infiltrate, particularly in the case of $H$. influenzae infection, that may mimic that of PCP $[1,51]$. Cavitation may be seen in the presence of P. aeruginosa, $S$. aureus, and $R$. equi infections $[1,45]$. Some studies have indicated a higher prevalence of complicated parapneumonic effusions with either S. pneumoniae or S. aureus [45].

\section{LABORATORY DIAGNOSIS OF PULMONARY INFECTION IN HIV/AIDS}

Although the principles of laboratory diagnosis of pulmonary infection in the setting of HIV/AIDS are based on conventional microbiological, immunological, radiological and histological strategies, interpretation is often complicated in advanced disease with atypical presentation. For example, in the case of HIV/M.tuberculosis co-infection, acid-fast bacilli sputum positivity, as well as cavitation and upper lobe infiltrates are less common in patients with severe immunosuppression [70], necessitating the acquisition of more sensitive procedures for the rapid detection of MTB in smear-negative sputum or other body fluids. One of the most promising of these is the GeneXpert MTB/RIF, an automated molecular diagnostic procedure which has a reported sensitivity and specificity for the detection of mycobacterial DNA in sputum of $86 \%$ and $>97 \%$ respectively [71]. IFN- $\gamma$-release assays (IGRAs) have limited utility in the diagnosis of active TB in HIV-infected patients with advanced disease in a high prevalence setting such as sub-Saharan Africa [72].

In the case of the pneumococcus, second only to M.tuberculosis as the major cause of opportunistic pneumonia in the HIV-infected in the developing world [70], confirmation of invasive disease has been improved by the acquisition of improved laboratory diagnostic 
procedures. Foremost amongst these are: i) quantitative real-time PCR procedures for the detection of pneumococcal DNA in biological fluids; and ii) the BINAX NOW Streptococcus pneumoniae immunochromatographic procedure which detects the $\mathrm{C}$-polysaccharide antigen in urine with good sensitivity and specificity in adult patients with invasive disease [73].

Laboratory diagnosis of opportunistic pneumonia caused by Pnuemocystis jirovecii, the third most frequently encountered respiratory pathogen in the HIV-infected in the developing world, is based on detection of the organism and/or its DNA using microscopy with specialized stains or molecular procedures respectively [70].

Recently, multiplex, molecular analytical procedures for the detection of bacterial and fungal DNA in biological fluids have become available. However, these are largely untested in the setting of advanced HIV infection in which interpretation may be complicated by the complexity of the lung microbiome, as well as by leakage of microbial nucleic acid from the GIT $[3,74]$.

\section{TREATMENT OF BACTERIAL CAP IN HIV INFECTED PERSONS}

There has not been any consensus on an appropriate diagnostic and treatment algorithm for patients with pulmonary infections in HIV infected patients overall [1]. While some have suggested that an aggressive invasive initial diagnostic approach should be followed, it is more commonly recommended that the patients should initially be treated empirically. This should be based on epidemiological evidence, and current clinical, and radiological features together with an aggressive non-invasive diagnostic approach. Thereafter, invasive techniques should be undertaken in patients not responding to initial therapy, in whom the diagnostic workup has not helpful [1]. One such approach is illustrated in Figure 1 [75]. While it is commonly recommended that a CD4 cell count should be performed as part of the diagnostic workup and may be helpful in indicating likely microbial 
etiology, this is potentially of limited value in that in a number of infections, including pneumococcal pneumonia, a transient and often substantial decrease in the CD4 cell count occurs $[1,34,76]$. This is reinforced by at least one additional study indicating that the outcome of HIV-infected patients with CAP is not predicted by the CD4 cell count (or even HIV-RNA levels) after adjusting for confounders [77]. However, others have suggested that the CD4 cell count should be considered as a crucial factor in the decision as to whether to admit HIV infected patients with bacterial CAP to hospital (Figure 2) [35].

The treatment of bacterial CAP is said to be similar to that of patients not infected with HIV infection, although no specific guidelines have been developed $[1,35,45]$. Antibiotic treatment should be directed at the most common bacterial pathogens and be modified according to subsequent microbiological findings [1]. Commonly the treatment recommended is the use of either a beta-lactam-macrolide combination or fluoroquinolone montherapy $[35,45,48]$. A large prospective multicenter international observational study of antibiotic treatment in patients with invasive pneumococcal disease (predominantly due to pneumonia), showed a positive impact of combination antibiotic therapy on outcome, even in the subset of patients that were HIV-infected [34]. One consideration with the use of fluoroquinolones in areas where tuberculosis is common is that empiric use of these agents in cases suspected as having CAP, but who actually have tuberculosis, may potentially be associated with masking of the tuberculosis diagnosis and/or development of drug resistance among the tuberculous microorganisms [45].

\section{MORTALITY}

While studies have indicated that the mortality of HIV infected patients with bacterial pneumonia may reach $30 \%$, most have indicated that the mortality is in the range of $10-15 \%$ [1]. In the post-HAART era, there appears to have been a decrease in the mortality, most 
probably due to the fact that infections with certain microbial pathogens (e.g. gram negative microorganisms), have become less common [1]. One area that has been particularly controversial, both in all cause CAP and specifically in pneumococcal pneumonia is whether the outcome is worse in HIV-infected versus HIV-uninfected persons [1]. While some studies have suggested that the outcome is no different $[1,78,79]$, more recent studies in both allcause CAP and pneumococcal pneumonia have suggested that the mortality of CAP is higher in HIV-infected patients $[1,35,69,82]$. In one of these studies, which was in patients with bacteraemic pneumococcal pneumonia, when cases were stratified according to age and severity of illness, HIV infected patients had a higher mortality with a significant trend for increasing mortality in those with lower CD4 cell counts [35,69]. For this reason some investigators have suggested that the CD4 cell count should be used as an indicator of the need for hospital admission of cases, as indicated previously [35].

Importantly, both bacterial pneumonia and PCP have been found to be associated with a decline in lung function (as measured by $\mathrm{FEV}_{1}, \mathrm{FVC}, \mathrm{FEV}_{1} / \mathrm{FVC}$ ratio and diffusing capacity of carbon monoxide) that persists following infection [81]. This highlights the importance of the prevention of opportunistic infections in HIV-infected persons.

\section{PREVENTION OF BACTERIAL CAP}

\section{General measures}

Given the considerable impact of bacterial CAP on HIV infected patients, aggressive strategies should be implemented for the prevention of such infections. This should be a comprehensive approach and include efforts to reduce drug and alcohol abuse, to initiate and assist with smoking cessation strategies, and to either initiate HAART in those fulfilling the citeria for such treatment or HAART adherence support programs for those already on such treatment [48]. These efforts should be combined with appropriate vaccination where this is available. 


\section{Immunoprophylaxis}

\section{Pneumococcal vaccine}

As mentioned above, those infected with HIV are at extremely high risk for development of invasive pneumococcal disease, which persists, albeit at lesser magnitude, following implementation of HAART. Pneumococcal vaccination strategies are clearly a priority in the setting of HIV infection and the current status of these has been covered in several recent reviews [34-36,38]. In summary, early studies undertaken in various geographical regions in the pre-/early HAART period using the 23 -valent pneumococcal polysaccharide vaccine were largely inconclusive with respect to efficacy. More recent studies undertaken in the post-HAART era have, however, established that the timing of immunization, particularly in relation to concomitant HAART, degree of immunosuppression, viral load, and presence of other risk factors, particularly cigarette smoking, is a major determinant of vaccine efficacy [34-36]. According to Hibberd, as reported in "UpToDate," the current recommendation of the CDC, NIH, and the HIV Medicine Association of the Infectious Diseases Society of America with respect to pneumococcal immunization, is "to administer pneumococcal vaccine to adults and children with CD4 counts of $>200 \mu \mathrm{l} / \mathrm{blood}$ as soon as HIV infection is diagnosed, providing that they have not had the vaccine during the previous five years" $[82,83]$. In those with CD4 counts of $<200 \mu \mathrm{l} /$ blood who had been previously immunized, re-vaccination could be considered when the CD4 count increased to $200 \mu \mathrm{l} /$ blood or higher following implementation of ART $[82,83]$. To sustain efficacy, a single re-vaccination is recommended after 5 years for the HIV-infected [82,84].

Future prospects with respect to improved efficacy of immunization include the development of novel conjugate vaccines which utilize highly-conserved, broadly serotypeunrestricted, recombinant surface and sub-surface pneumococcal protein antigens as carriers 
of capsular polysaccharides [37]. Ideally, these should confer much broader coverage than current vaccines in the setting of induction of both cell-mediated (Th1/Th17-based) and humoral protective immune responses [37,38].

\section{Haemophilus influenzae}

Most cases of severe H.influenzae infection in HIV-infected persons occurring with advanced immunosuppression involve non-typeable strains of this pathogen [42]. Accordingly, immunization of adults, unlike children, with H.influenzae type B (Hib) conjugate vaccine is not recommended $[82,83]$, although this situation may change with the development of novel vaccines based on conserved surface proteins [85]. In the case of children, both HIV-infected and -uninfected, high rates of Hib conjugate vaccine failure have raised concerns about current immunization schedules [86].

\section{REFERENCES}

1. Benito N, Moreno A, Miro JM, et al. Pulmonary infections in HIV-infected patients: an update in the $21^{\text {st }}$ century. Eur Respir J 2012; 39: $730-45$.

2. Morris A, Crothers K, Beck JM, et al. An Official ATS Workshop Report: Emerging issues and current controversies in HIV-associated pulmonary diseases. Proc Am Thorac Soc 2011;8:17-26.

3. Segal LN, Methé BA, Nolan A, et al. HIV-1 and bacterial pneumonia in the era of antiretroviral therapy. Proc Am Thorac Soc 2011;8:282-7.

4. Schacker T. The role of secondary lymphatic tissue in immune deficiency of HIV infection. AIDS 2008;22(suppl 3):S13-S18.

5. Brenchley JM, Knox KS, Asher AI, et al. High frequencies of polyfunctional HIVspecific $\mathrm{T}$ cells are associated with preservation of mucosal CD4 T cells in bronchoalveolar lavage. Mucosal Immunol 2008;1:49-58.

6. Brenchley JM, Paiardini M, Knox KS, et al. Differential Th 17 CD4 T-cell depletion in pathogenic and nonpathogenic lentiviral infections. Blood 2008;112:2826-35. 
7. Lefrançois L, Puddington L. Intestinal and pulmonary mucosal T cells: Local heroes fight to maintain the status quo. Annu Rev Immunol 2006;24:681-704.

8. Moyron-Quiroz J, Rangel-Moreno J, Carragher DM, et al. The function of local lymphoid tissues in pulmonary immune responses. Adv Exp Med Biol 2007;590:5568.

9. Parker D, Prince A. Innate immunity in the respiratory epithelium. Am J Respir Cell Mol Biol 2011;45:189-201.

10. Collini P, Noursadeghi M, Sabroe I, et al. Monocyte and macrophage dysfunction as a cause of HIV-1 induced dysfunction of innate immunity. Curr Mol Med 2010;10:72740.

11. Alexaki A, Wigdahl B. HIV-1 infection of bone marrow hematopoietic progenitor cells and their role in trafficking and viral dissemination. PLoS Pathog 2008;4(12):e1000215.

12. van Kooyk Y, Geijtenbeek TBH. DC-SIGN: escape mechanism for pathogens. Nature Rev Immunol 2003;3:697-709.

13. Da Silva RC, Segat L, Crovella S. Role of DC-SIGN and L-SIGN receptors in HIV-1 vertical transmission. Hum Immunol 2011;72:305-11.

14. Coleman CM, Wu L. HIV interactions with monocytes and dendritic cells: viral latency and reservoirs. Retrovirol 2009;6:51.

15. Pritschet K, Donhauser N, Schuster P, et al. CD4- and dynamin-dependent endocytosis of HIV-1 into plasmacytoid dendritic cells. Virology 2012;423:152-64.

16. Liao Z, Roos JW, Hildreth JEK. Increased infectivity of HIV type 1 particles bound to cell surface and solid phase ICAM-1 and VCAM-1 through acquired adhesion molecules LFA-1 and VLA-4. AIDS Res Hum Retrovirus 2000;16:355-66.

17. Conaldi PG, Serra C, Dolei A, et al. Productive HIV-1 infection of human vascular endothelial cells requires cell proliferation and is stimulated by combined treatment with interleukin-1 beta plus tumor necrosis factor-alpha. J Med Virol 1995;47:355-63.

18. Mattapallil JJ, Douek DC, Hill B, et al. Massive infection and loss of memory $\mathrm{CD}^{+}{ }^{+} \mathrm{T}$ cells in multiple tissues during acute SIV infection. Nature 2005;434:1093-7.

19. Li Q, Duan L, Estes JD, et al. Peak SIV replication in resting memory CD4 ${ }^{+} \mathrm{T}^{-}$cells depletes gut lamina propria CD4 ${ }^{+} \mathrm{T}$ cells. Nature 2005;434:1148-52.

20. Boasso A, Shearer GM. Chronic innate immune activation as a cause of HIV-1 immunopathogenesis. Clin Immunol 2008;126:235-42. 
21. Borrow P, Shattock RJ, Vyakarnam A. Innate immunity against HIV: a priority target for HIV prevention research. Retrovirol 2010;7:84.

22. Masten BJ, Olson GK, Tarleton CA, et al. Characterization of myeloid and plasmacytoid dendritic cells in human lung. J Immunol 2006;177:7784-93.

23. Schmidt B, Ashlock BM, Foster H, et al. HIV-infected cells are major inducers of plasmacytoid dendritic cell interferon production, maturation and migration. Virology 2005;343:256-66.

24. Barber GN. Cytoplasmic DNA innate immune pathways. Immunol Rev 2011;243:99108.

25. Herbeuval JP, Hardy AW, Boasso A, et al. Regulation of TNF-related apoptosisinducing ligand on primary $\mathrm{CD}^{+}{ }^{+} \mathrm{T}$ cells by HIV-1: role of type I IFN-producing plasmacytoid dendritic cells. Proc Natl Acad Sci U S A 2005;102:13974-9.

26. Herveuval JP, Grivel JC, Boasso A, et al. CD4 ${ }^{+}$T-cell death induced by infectious and non-infectious HIV-1: role of type 1 interferon-dependent, TRAIL/DR5-mediated apoptosis. Blood 2005;106:3524-31.

27. Fraietta J, Mueller Y, Do D, et al. Type 1 interferon increases the sensitivity of human immunodeficiency virus (HIV)-specific $\mathrm{CD}^{+} \mathrm{T}$ lymphocytes to CD95/Fas-mediated apoptosis. J Immunol 2010;184(Abstract):42.22.

28. Langlois RA, Legge KL. Plasmacytoid dendritic cells enhance mortality during lethal influenza infections by eliminating virus-specific CD8 T cells. J Immunol 2010;184:4440-4446.

29. Labidi-Galy SI, Sisirak V, Meeus P, et al. Quantitative and functional alterations of plasmacytoid dendritic cells contribute to immune tolerance in ovarian cancer. Cancer Res 2011;71:5423-34.

30. Dumitriu IE, Dunbar DR, Howie SE, et al. Human dendritic cells produce TGF-beta 1 under the influence of lung carcinoma cells and prime the differentiation of $\mathrm{CD}^{+} \mathrm{CD} 25^{+} \mathrm{Foxp}^{+}$regulatory T cells. J Immunol 2009;182:2795-807.

31. Zeng M, Smith AJ, Wietgrefe SW, et al. Cumulative mechanisms of lymphoid tissue fibrosis and T cell depletion in HIV-1 and SIV infections. J Clin Invest 2011;121:9981008.

32. Zeng M, Paiardini M, Engram JC, et al. Critical role for CD4 T cells in maintaining lymphoid tissue structure for immune cell homeostasis and reconstitution. Blood 2012 [Epub ahead of print]. 
33. Nies-Kraske E, Schacker TW, Condoluci D, et al. Evaluation of the pathogenesis of decreasing CD4(+) T cell counts in human immunodeficiency virus type 1-infected patients receiving successfully suppressive antiretroviral therapy. J Infect Dis 2009;199:1648-56.

34. Feldman C. Pneumonia associated with HIV infection. Curr Opin Infect Dis 2005; 18:165-70.

35. Madeddu G, Fiori ML, Mura MS. Bacterial community-acquired pneumonia in HIVinfected patients. Curr Opin Pulm Med 2010;16:201-7.

36. Raju R, Peters BS, Breen RAM. Lung infections in the HIV-infected adult. Curr Opin Pulm Med 2012;18:253-8.

37. Anderson R, Feldman C. Key virulence factors of Streptococcus pneumoniae and non-typeable Haemophilus influenzae: roles in host defence and immunisation. South African Journal of Epidemiology and Infection 2011;26:6-12.

38. Malley R, Anderson PW. Serotype-independent pneumococcal experimental vaccines that induce cellular as well as humoral immunity. Proc Natl Acad Sci U S A 2012;109:3623-7.

39. Glennie SJ, Sepako E, Mzinza D, et al. Impaired T cell memory response to Streptococcus pneumoniae precedes CD4 T cell depletion in HIV-infected Malawian adults. PLoS One 2011;6(9):e25610.

40. Kuritzkes DR. Neutropenia, neutrophil dysfunction, and bacterial infection in patients with human immunodeficiency virus disease: the role of granulocyte colonystimulating factor. Clin Infect Dis 2000;30:256-60.

41. Engelich G, Wright DG, Hartshorn K. Acquired disorders of phagocyte function complicating medical and surgical illness. Clin Infect Dis 2001;33:2040-8.

42. Feldman C, Anderson R. Antibiotic resistance of pathogens causing communityacquired pneumonia. Semin Respir Crit Care Med 2012;33:232-43.

43. Cordero E, Pachón J, Rivero A, et al. Haemophilus influenzae pneumonia in human immunodeficiency virus-infected patients. Clin Infect Dis 2000;30:461-5.

44. Steinhart R, Reingold AL, Taylor F, et al. Invasive Haemophilus influenzae infections in men with HIV infection. JAMA 1992;268:3350-2.

45. Huang L, Crothers K. HIV-associated opportunistic pneumonias. Respirology 2009; 14: $474-485$.

46. Feikin DR, Feldman C, Schuchat A, et al. Global strategies to prevent bacterial pneumonia in adults with HIV disease. Lancet 2004; 4: $445-455$. 
47. Hirschtick RE, Glassroth J, Jordan MC, et al. Bacterial pneumonia in persons infected with the human immunodeficiency virus. N Engl J Med 1995; 333: 845 51.

48. Madeddu G, Fois AG, Pirina P, et al. Pneumococcal pneumonia: clinical features, diagnosis and management in HIV-infected and HIV noninfected patients. Curr Opin Pulm Med 2009; 15: $236-42$.

49. Feldman JG, Minkoff H, Schneider MF, et al. Association of cigarette smoking with HIV prognosis among women in the HAART Era: A report from the Women's Interagency HIV Study. Am J Public Health 2006; 96: 1060 - 5.

50. Wolff AF, O'Donnell AE. Pulmonary manifestations of HIV infection in the era of highly active antiretroviral therapy. Chest 2001; 120: 1888 - 93.

51. Rosen MJ. Pulmonary complications of HIV infection. Respirology 2008; 13: 181 $-90$.

52. Gordin FM, Roediger MP, Girard P-M, et al. Pneumonia in HIV-infected persons. Increased risk with cigarette smoking and treatment interruptions. Am J Respir Crit Care Med 2008; 178: $630-6$.

53. Bénard A, Mercié P, Alioum A, et al. Bacterial pneumonia among HIV-infected patients: Decreased risk after tobacco smoking cessation. ANRS CO3 Aquitaine Cohort, 2000-2007. Plos One 2010; 5: e8896.

54. Hull MW, Phillips P, Montaner JSG. Changing global epidemiology of pulmonary manifestations of HIV/AIDS. Chest 2008; 134: 1287 - 98.

55. Siemieniuk RAC, Gregson DB, Gill MJ. The persisting burden of invasive pneumococcal disease in HIV patients: an observational cohort study. BMC Infectious Diseases 2011; 11: 314.

56. Nunes MC, von Gottberg A, de Gouveia L, et al. Persistent high burden of invasive pneumococcal disease in South African HIV-infected adults in the era of an antiretroviral treatment program. Plos One 2011; 6: e27929.

57. Schleicher GK, Feldman C. Dual infection with Streptococcus pneumoniae and Mycobacterium tuberculosis in HIV-seropositive patients with community acquired pneumonia. Int J Tuberc Lung Dis 2003; 7: 1207-8.

58. Cordero E, PachÓn J, Rivero A, et al. Haemophilus influenzae pneumonia in human immunodeficiency virus- infected patients. Clin Infect Dis 2000; 30: 461 - 5. 
59. Popovich KJ, Weinstein RA, Aroutcheva A, et al. Community-associated methicillinresistant Staphylococcus aureus and HIV: Intersecting epidemics. Clin Infect Dis 2010; 50: $979-87$.

60. Levine SJ, White DA, Fels AO. The incidence and significance of staphylococcus aureus in respiratory cultures from patients infected with the human immunodeficiency virus. Am Rev Respir Dis 1990; 141: 89 - 93.

61. Fuijitani S, Sun H-Y, Yu VL, et al. Pneumonia due to Pseudomonas aeruginosa: Part I: Epidemiology, clinical diagnosis, and source. Chest 2011; 139: 909 - 19.

62. Manfredi R, Nanetti A, Ferri M, et al. Pseudomonas spp. complications in patients with HIV disease: An eight-year clinical and microbiological survey. Eur J Epidemiol 2000; 16: $111-18$.

63. Pedro-Botet ML, Sabrià M, Sopena N, et al. Legionnaires disease and HIV infection. Chest 2003; 124: $543-47$.

64. Pedro-Botet ML, Sopena N, Garcĺa-Cruz A, et al. Streptococcus pneumoniae and Legionella pneumophila pneumonia in HIV-infected patients. Scand J Infect Dis 2007; 39: $122-28$.

65. Topino S, Galati V, Grilli E, et al Rhodococcus equi infection in HIV-infected individuals: Case reports and review of the literature. AIDS PATIENT CARE and STDs 2010; 24: $211-22$.

66. Manfredi R, Nanetti A, Valentini R, et al. Moraxella catarrhalis pneumonia during HIV disease. J Chemother 2000; 12: $406-11$.

67. Minero MV, Marin M, Cercenado E, et al. Nocardiosis at the turn of the century. Medicine 2009; 88: $250-61$.

68. Menéndez R, Cordero PJ, Santos M, et al. Pulmonary infection with Nocardia species: a report of 10 cases and review. Eur Respir J 1997; 10: 1542 - 46.

69. Feldman C, Klugman KP, Yu VL, et al. Bacteraemic pneumococcal pneumonia: Impact of HIV on clinical presentation and outcome. J Infect 2007; 55: $125-35$.

70. Feldman C, Anderson R. Respiratory infections in specific populations: HIV patients. In: Blasi F, Dimopoulos G. eds. Textbook of Respiratory and Critical Care Infections. Jaypee Brothers Medical Publishers, India (in press).

71. Scott LE, McCarthy K, Gous N, et al. Comparison of Xpert MTB/RIF with other nucleic acid technologies for diagnosing pulmonary tuberculosis in a high HIV prevalence setting: A prospective study. PLoS Med 2011;8(7):e1001061. 
72. Cattamanchi A, Ssewenyana I, Davis JL, et al. Role of interferon-gamma release assays in the diagnosis of pulmonary tuberculosis in patients with advanced HIV infection. BMC Infect Dis 2010;10:75.

73. Smith MD, Sheppard CL, Hogan A, et al. Diagnosis of Streptococcus pneumoniae infection in adults with bacteremia and community-acquired pneumonia: clinical comparison of pneumococcal PCR and urinary antigen dedtection. J Clin Microbiol 2009;47:1046-9.

74. Streubens MJ. Detection of microbial DNAemia: does it matter for sepsis management? Intensive Care Med 2010;36:193-195.

75. Feldman C, Brink AJ, Richards G et al. Working Group of the South African Thoracic Society. Management of community-acquired pneumonia in adults. S Afr Med J 2007; 97: 1296 - 306.

76. Schleicher GK, Hopley MJ, Feldman C. CD4 T-lymphocyte subset counts in HIVseropositive patients during the course of community-acquired pneumonia caused by Streptococcus pneumoniae. Clin Microbiol Infect 2004; 10: 587 - 89.

77. Bordon J, Kapoor R, Martinez C, et al. CD4+ cell counts and HIV-RNA levels do not predict outcomes of community-acquired pneumonia in hospitalized HIV-infected patients. Int J Infect Dis 2011; 15: e822 - e827.

78. Malinis M, Myers J, Bordon J, et al. Clinical outcomes of HIV-infected patients hospitalized with bacterial community-acquired pneumonia. Int J Infect Dis 2010; 14: e22-ee27.

79. Feldman C, Glatthaar M, Morar R, et al. Bacteremic pneumococcal pneumonia in HIV-seropositive and HIV-seronegative adults. Chest 1999; 116: $107-14$.

80. Kohli R, Lo Y, Homel P, et al. Bacterial pneumonia, HIV therapy, and disease progression among HIV-infected women in the HIV Epidemiologic Research (HER) Study. Clin Infect Dis 2006; 43: $90-8$.

81. Morris AM, Huang L, Bacchetti P, et al. Permanent declines in pulmonary function following pneumonia in human immunodeficiency virus-infected persons. Am J Respir Crit Care Med 2000; $162 ; 612-16$.

82. Hibberd PL. Immunizations in HIV-infected patients. In UpToDate® 2012. Available at http://www.uptodate.com/contents/immunizations-in-hiv-infected-patients. Accessed May 24, 2012.

83. Kaplan JE, Benson C, Holmes KH, et al. Guidelines for prevention and treatment of opportunistic infections in HIV-infected adults and adolescents: recommendations 
from CDC, the National Institutes of Health, and the HIV Medicine Association of the Infectious Diseases Society of America. MMWR Recomm Rep 2009;58(RR-4):1-207.

84. Advisory Committee on Immunization Practices. Recommended adult immunization schedule: United States, 2009. Ann Intern Med 2009;150:40-4.

85. Murphy TF. Current and future prospects for a vaccine for nontypeable Haemophilus influenzae. Curr Infect Dis Rep 2009;11:177-82.

86. Crowther-Gibson P, Cohen C, Klugman KP, et al. Risk factors for multidrug-resistant invasive pneumococcal disease in South Africa, 2003-2008: the pre-vaccine era in a high HIV prevalence setting. Antimicrob Agents Chemother 2012 [Epub ahead of print]. 


\section{Box 1 Risk factors for bacterial CAP in HIV infected patients}

- Cigarette and illicit drug smoking

- IVI drug abuse

- Older age

- Detectable HIV viral load

- Lower CD4 cell count

- Previous pneumonia

- Underlying co-morbid conditions (including cardiovascular, renal disease, respiratory diseases, hepatic cirrhosis, alcoholism)

- Lower socioeconomic status

- Genetic factors? 
BOX 2 Bacterial etiology of community-acquired pneumonia in HIV infected persons

- Most common
- Streptococcus pneumoniae
○ Haemophilus influenzae

- Not infrequent
- Staphylococcus aureus
- Klebsiella pneumoniae

- Less common

- Atypical pathogens

- Uncommon/Unusual infections
- Rhodococcus equi
- Pseudomonas aeruginosa 
Table 1: Mechanisms by which HIV-mediated chronic activation of plasmacytoid dendritic cells contributes to dysfunction and depletion of $\mathrm{T}$ cells

\section{$\underline{\text { Mechanism }}$}

Excessive production of IFN- $\alpha$

Increased activity of indoleamine

2,3-dioxygenase

Acquisition of expression of CCR7

Increased synthesis of the cytokine, transforming growth factor- $\beta$ (TGF- $\beta$ )

\section{Consequence}

Apoptosis of $\mathrm{CD}^{+}$and $\mathrm{CD} 8^{+} \mathrm{T}$ cells

Acquisition of a tolerogenic

phenotype with resultant suppression

of $\mathrm{T}$ cell responses

Enables migration of HIV-infected,

activated plasmacytoid dendritic

cells to lymphoid tissue

Promotes: i) the generation of

immunosuppressive $\mathrm{CD} 4^{+}, \mathrm{CD} 25^{+}$,

FoxP $3^{+}$regulatory $\mathrm{T}$ cells; and ii)

collagen deposition in lymphatic

tissues, resulting in disruption of

architecture and failure to maintain $\mathrm{T}$

cell populations 
Table 2: HIV-mediated alterations in innate and adaptive immune mechanisms which predispose to severe pneumococcal disease

\section{Abnormality}

$\downarrow$ Production and reactivity of anticapsular antibodies of the $\operatorname{Ig} \mathrm{A}$ and IgG classes, as well as antibodies to pneumococcal protein surface adhesins

$\downarrow$ Mobilization and activation of neutrophils / monocytes / alveolar macrophages

$\downarrow$ Production of neutrophils and monocytes in the bone marrow

\section{$\underline{\text { Mechanism }}$}

$\downarrow$ Numbers of Th1 and Th2

effector / memory cells, as well as antigen-specific $\mathrm{T}$ cells

\section{$\underline{\text { References }}$} \\ 37,38}

$\downarrow$ Production of IL-17 and IFN-

$\gamma$ due to loss of Th1 and Th17

cells, as well as to intrinsic

defects in these cells

Dysfunction of progenitor

40,41

cells 
Legend to the Figures

Figure 1. An algorithmic approach to the evaluation of hospitalized HIV-seropositive patients with community-acquired pneumonia, based on the chest radiographic features. This needs to be considered in conjunction with the clinical features. (Figure from Feldman C. Bacterial pneumonia in the HIV-seropositive patient. CME 2001; 19: 390-394, reproduced with permission).

Figure 2. Proposed flowchart for the management of HIV-infected patients with bacterial community-acquired pneumonia. (Figure reproduced from Maddedu G, Fiori ML, Mura MS. Bacterial community-acquired pneumonia in $\mathrm{HIV}$-infected patients. Curr Opin Pulm Med 2010; 16: 201-207, with permission). 
Figure 1

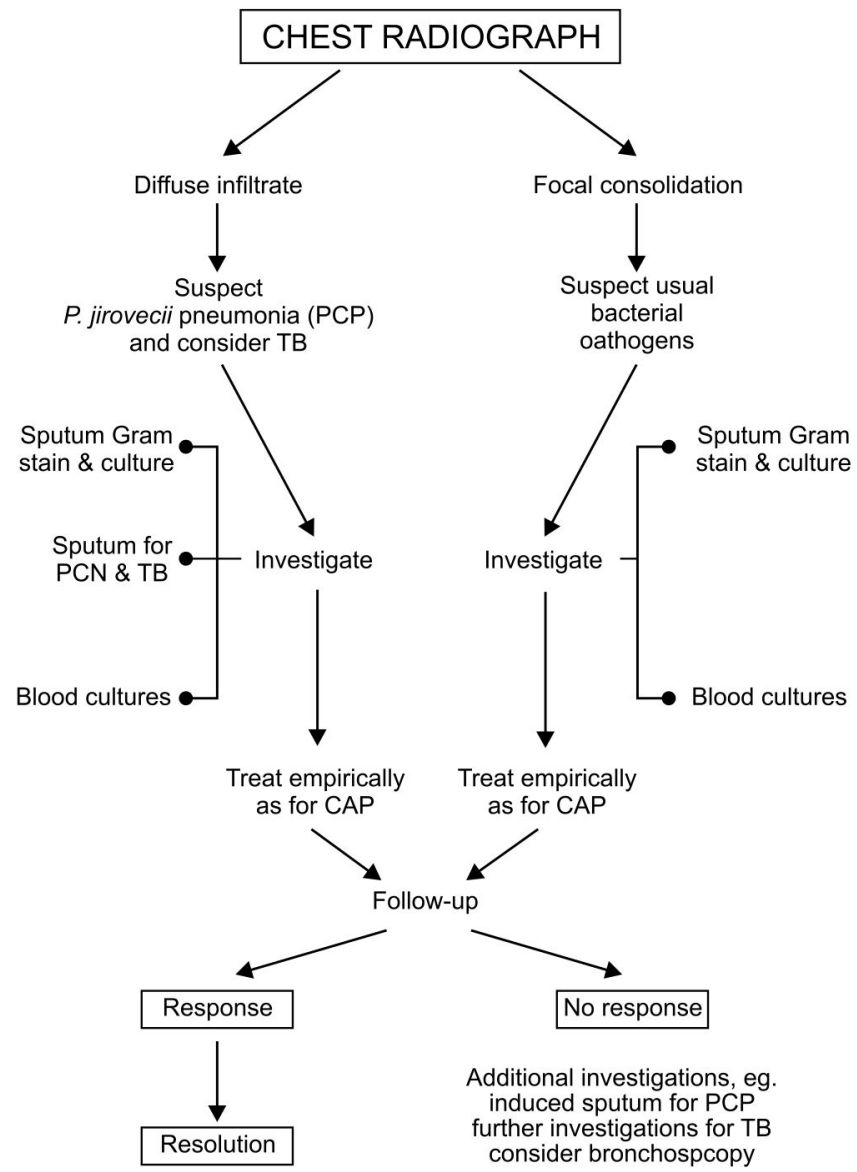




\section{Figure 2}

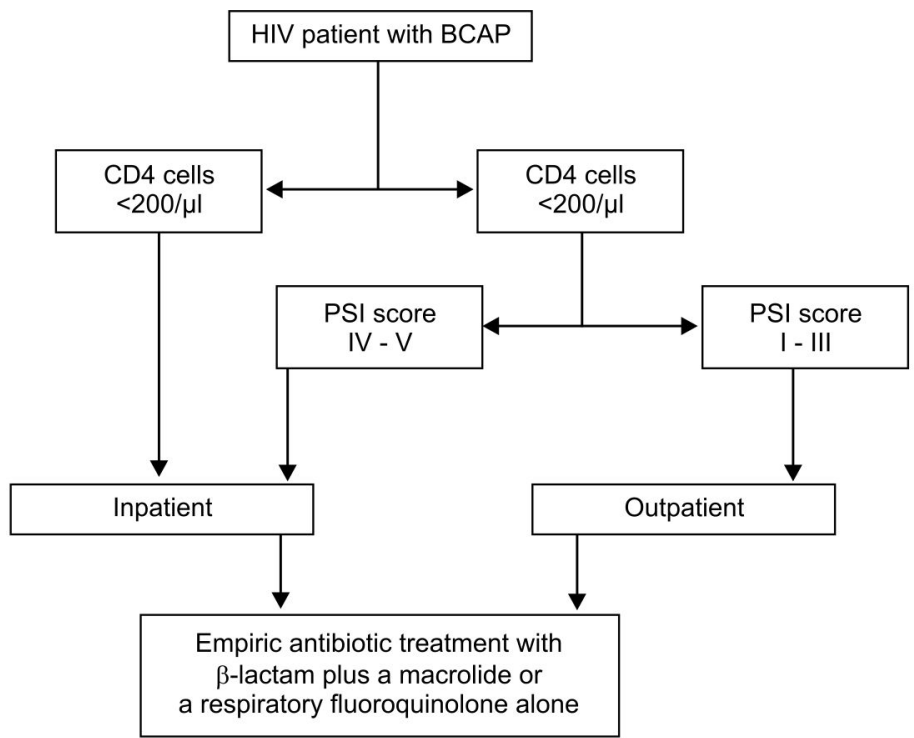

In HIV-infected patients with BCAP, CDd4 cell count should be evaluated. Patients with a Cd 4 cell count of $<200$ cells/ $\mu$ l should be always hospitalized, whereas those with a Cd4 count of at least $200 \mathrm{cells} / \mu \mathrm{l}$ could be managed according to PSI. Both inpatients and outpatients should start empiric antibiotic therapy with a $\beta$-lactam and a macrolide or a respiratory fluoroquinolone alone. BCAP, community-acquired pneumonia; PSI pneumonia severity index. 